IOS Press

\title{
Thermal degradation kinetics of monomeric anthocyanins, colour changes and storage effect in elderberry juices
}

\author{
Carolina Busso Casati ${ }^{\mathrm{a}}$, Rosa Baeza ${ }^{\mathrm{a}, *}$, Virginia Sanchez $^{\mathrm{a}}$, Alejandra Catalano ${ }^{\mathrm{b}}$, Paula López $^{\mathrm{b}}$ \\ and María Clara Zamora ${ }^{\mathrm{a}, \mathrm{c}}$ \\ ${ }^{a}$ Facultad de Ciencias Agrarias, Pontificia Universidad Católica Argentina (UCA), Cap. Gral. Ramón Freire 183, \\ Buenos Aires, Argentina \\ ${ }^{\mathrm{b}}$ Cátedra de Farmacognosia - IQUIMEFA (UBA-CONICET), Facultad de Farmacia y Bioquímica, UBA-CONICET, \\ Junín 953, Buenos Aires, Argentina \\ ${ }^{\mathrm{c}}$ Member of Consejo Nacional de Investigaciones Científicas y Técnicas (CONICET), Rivadavia 1917, Buenos Aires, \\ Argentina
}

Submitted 27 November 2014; accepted 8 January 2015

\begin{abstract}
.
BACKGROUND: Elderberry (Sambucus nigra L.) is considered an interesting fruit as food ingredient, due to its high content of anthocyanins that give products an attractive red colour.

OBJECTIVE: The aim of present study was to evaluate the kinetics of elderberry monomeric anthocyanin (MAcy) and colour degradation due to thermal processing and storage.

METHODS: Anthocyanins content was measured with $\mathrm{pH}$-differential method. CIELab parameters were obtained with a Minolta Spectrophotometer, total phenolics were determined by Folin-Ciocalteu method. MAcy degradation and evolution of colour parameter a* were fitted to a first-order model.

RESULTS: The degradation rate of $\mathrm{a}^{*}$ was about three times lower than MAcy degradation rate. Activation energy for degradation of $\mathrm{a}^{*}$ and MAcy were 140.6 and $144.6 \mathrm{~kJ} \mathrm{~mol}^{-1}$ respectively. Degradation rates (k) obtained during storage were $0.025 \mathrm{~d}^{-1}$ for MAcy and $0.0064 \mathrm{~d}^{-1}$ for $\mathrm{a}^{*}$. During storage, $50 \%$ reduction of initial values was at 120 days for MAcy and at 432 days for colour parameter $\mathrm{a}^{*}$ at $25^{\circ} \mathrm{C}$. However, a high retention of polyphenols and antioxidant was noted.

CONCLUSIONS: Kinetic parameters calculated for elderberry juice can be used to design a thermal treatment to obtain a high retention of colour and bioactive compounds.
\end{abstract}

Keywords: Anthocyanins, colour, kinetics, polyphenols, thermal processing, antioxidant

\section{Introduction}

The development of products based on berries is gaining importance due to their potential use as a food ingredient, natural colorant and nutraceutical. Among them, elderberry (Sambucus nigra L.) stands out for its high content of anthocyanins that give products an attractive red colour, in addition to its rich composition of other polyphenols, essential amino acids, vitamin $\mathrm{C}$ and minerals. Moreover, elderberry juice presents high phenolic content and antioxidant activity [1-3].

*Corresponding author: Rosa Baeza, Facultad de Ciencias Agrarias, Pontificia Universidad Católica Argentina (UCA), Cap. Gral. Ramón Freire 183, 1426 Buenos Aires, Argentina. Tel./Fax: +54 114552 2711; E-mail: rosabaezabsas@yahoo.com.ar. 
Numerous studies have reported the effects of elderberry's anthocyanins as an antioxidant, anticarcinogenic and immune-stimulating agents among other health benefits [4-6]. Anthocyanin pigments are labile compounds that easily degrade following various reaction mechanisms affected by temperature and $\mathrm{pH}$. Their stability is highly variable depending on their structure and the composition of the matrix in which they exist [7]. Degradation of these compounds has an effect on product quality and therefore consumer acceptance [8].

Different thermal treatments are performed in products based on berries during the processing steps, with the aim of produce safety and acceptable shelf-life products. These processes, which generally involve temperatures lower than $100^{\circ} \mathrm{C}$ in acidic products, could lead to the degradation of anthocyanins and product quality [9]. The effect will be dependent on the length of time and treatment applied, so that the knowledge of the kinetic parameters of these processes (reaction rates, activation energy, and average response time) will be essential to predict changes that will occur in the products during processing. Based on current knowledge it is not possible to predict the effect of thermal treatment on anthocyanin retention [10].

Likewise, products based on fruit juice, bottled and pasteurized in general have a long shelf life (1-3 years) at room temperature. During this storage time adverse effects may occur which affect the stability of anthocyanins and consequent changes in colour characteristics. The aim of the present study was to evaluate the kinetics of elderberry anthocyanin degradation due to thermal processing and storage time, and its relation to the colour change parameters. Furthermore, other variables such as antioxidant capacity during storage were also evaluated.

\section{Materials and methods}

\subsection{Samples}

Elderberry juice and pulp were provided by a producer from El Bolsón, Río Negro (Argentina). Elderberry fruits used by the producer were of similar maturation degree, collected in areas next to El Bolsón. The elderberry juice was made with fruit pulp which was obtained from fruit blanched $\left(80^{\circ} \mathrm{C}, 3 \mathrm{~min}\right)$ and then packed, pasteurized and frozen.

The juice was formulated based on $74 \%$ pulp, $26 \%$ sucrose, $0.05 \%$ xanthan gum, $0.06 \%$ potassium sorbate and $0.05 \%$ ascorbic acid. The juice was packaged in $500 \mathrm{~mL}$ glass-covered bottles, pasteurized $\left(80^{\circ} \mathrm{C}, 30 \mathrm{~min}\right)$ and stored during shelf life.

\subsection{Heat treatment of elderberry pulp to obtain kinetic parameters}

Elderberry pulp (processed as described in 2.1) was thawed and put in Pyrex tubes, well capped to avoid evaporation and placed in a water bath at constant temperature of $70^{\circ} \mathrm{C}, 80^{\circ} \mathrm{C}$ and $90^{\circ} \mathrm{C}$. At regular time intervals, samples were removed from the bath, cooled by plunging into ice water and then stored at $-18^{\circ} \mathrm{C}$ until they were analyzed. In order to obtain kinetic parameters (degradation rates, half-life times, activation energies), the total heating times at each temperature were selected based on previous studies' data [11-14]. These experimental times are generally longer than those used in industrial processes.

\subsection{Storage of elderberry juice}

The storage of juice bottles was performed in darkness at $40^{\circ} \mathrm{C}$ for 140 days. Two bottles of juice were selected at $0,15,30,60$, and 140 days to take measurements. The time and temperature of storage were selected taking into account previous studies of anthocyanin's degradation which reported a temperature quotient $\left(\mathrm{Q}_{10}\right)$ value about 2.5 $[11,12]$. Therefore, the degradation rate at $40^{\circ} \mathrm{C}$ would be 4 times faster than at $25^{\circ} \mathrm{C}$; and 18 months of storage $(540$ days) at $25^{\circ} \mathrm{C}$ would be equivalent to 140 days at $40^{\circ} \mathrm{C}$.

\subsection{Preparation of extract from elderberry pulp and juice}

Elderberry pulp thermically treated and juice bottles removed from storage at different times were used to prepare alcoholic extracts using $5 \mathrm{~g}$ of pulp or juice. Samples were extracted twice in $20 \mathrm{ml}$ ethanol: $\mathrm{HCl} 0.1 \mathrm{~N}$ 
(85:15), (solvents were acquired from Merck, Darmstadt, Germany). Samples were centrifuged and supernatant were mixed and utilized for measurements of total phenolics, monomeric anthocyanins, colour, colour density and polymeric colour. All the results are based on juice taking into account a juice density of $1.15 \mathrm{~g} / \mathrm{ml}$ at $25^{\circ} \mathrm{C}$ for unit calculations.

\subsection{Methods}

\subsubsection{Physicochemical properties}

Total soluble solids content was evaluated in ${ }^{\circ}$ Brix with a manual refractometer Atago N2 (Tokyo, Japan). pH measurements were taken at $25^{\circ} \mathrm{C}$ using Hanna HI 8424 equipment (Hanna Instruments Inc., Woonsocket, RI, USA).

\subsubsection{Total phenolics}

Total phenolics (TP) were determined on the extracts using the Folin- Ciocalteu method according to Waterhouse [15], (Folin-Ciocalteu reagent was purchased from Merck KgaA Darmstadt, Germany). Sample absorbance at $765 \mathrm{~nm}$ (spectrophotometer Shimadzu PharmaSpecUV-1700) was measured, and phenolic concentrations were expressed as Gallic acid equivalent (GAE) in $\mathrm{g} / \mathrm{L}$ calculated by means of a standard curve of Gallic acid (obtained from Anedra, Buenos Aires, Argentina).

\subsubsection{Monomeric anthocyanin content}

Monomeric anthocyanin content (MAcy) of juice extracts was determined by $\mathrm{pH}$ differential method described by Giusti and Wrolstad [16], using potassium chloride buffer ( $\mathrm{pH} \mathrm{1.0)} \mathrm{and} \mathrm{sodium} \mathrm{acetate} \mathrm{buffer} \mathrm{(} \mathrm{pH}$ 4.5). A sample of pulp or juice extract were mixed with corresponding buffer, in a dilution to achieve an adequate reading of absorbance, that was read at 510 and $700 \mathrm{~nm}$. Monomeric anthocyanin content was expressed as cyanidin-3-glucoside in mg/L according to the following equation:

$$
\operatorname{MAcy}(\mathrm{mg} / \mathrm{L})=\mathrm{A} \cdot \mathrm{MW} \cdot \mathrm{DF} \cdot 1000 /(\varepsilon \cdot 1)
$$

where $\mathrm{A}=\left(\mathrm{A}_{510}-\mathrm{A}_{700}\right)_{\mathrm{pH} 1}-\left(\mathrm{A}_{510}-\mathrm{A}_{700}\right)_{\mathrm{pH} 4.5} ; \mathrm{MW}$ (molecular weight $)=449.2 \mathrm{~g} / \mathrm{mol}$ for cyaniding-3-glucoside; $\mathrm{DF}=$ dilution factor, $\varepsilon=26900$ is the molar extinction coefficient in $\mathrm{L} / \mathrm{mol} / \mathrm{cm} ; 1=$ path length in $\mathrm{cm}$.

\subsubsection{Analysis of anthocyanin content by HPLC}

HPLC analysis was carried out according to the method reported by Hager et al. [17] in a Varian HPLC Serie 900. The injection volume was $20 \mu \mathrm{l}$ of juice extract. Separation was achieved on a reverse phase C18 Gemini ${ }^{\circledR}$ $150 \times 4,6 \mathrm{~mm} ; 5 \mu \mathrm{m}$ column. Detection was performed using a diode array detector. Two solvents were used during the analysis. Solvent A: distilled water/formic acid (95/5) and solvent B: methanol (HPLC solvents from Merck KgaA Darmstadt, Germany). A constant flow of $1 \mathrm{ml} / \mathrm{min}$ was applied with a linear gradient elution profile. The proportions of solvent A used were: $98 \%$ to $40 \%$ in $60 \mathrm{~min}$. An external calibration curve of Cyanidin-3-glucoside (Cy3glc, purchased from Sigma-Aldrich, USA) was used for quantification, in the range 10-100 $\mu \mathrm{g} / \mathrm{ml}$. The content of total anthocyanins (TAcy HPLC) and Cy3glc content was analyzed by absorption at $515 \mathrm{~nm}$ and the results expressed in $\mathrm{mg}$ cyanidin equivalents per litter of elderberry juice $(\mathrm{mg} \mathrm{Cy} 3 \mathrm{glc} / \mathrm{L})$. The sample was prepared in duplicate and then analyzed.

\subsubsection{Antioxidant capacity}

The antioxidant activity of juice was measured on the basis of the scavenging activity of the stable 1,1-diphenyl2-picrylhydrazyl free radical (DPPH). An aliquot of each methanolic solution enriched with a juice sample (1 mg/L) was added to a methanolic solution of DPPH $(25 \mathrm{mg} / \mathrm{L})$ and the changes caused in absorbance, were measured at $517 \mathrm{~nm}$ as a function of the elapsed time. A calibration curve was prepared using Trolox as standard (DPPH and Trolox from Sigma Chemical, USA). Results were expressed as mmol Trolox/ $\mathrm{mL}$ of juice [18].

\subsubsection{Colour measurements}

The colour of the juice was analyzed using a Minolta Spectrophotometer CM-600d (Konica Minolta Observer), with D65 illuminant, and an observer angle of $2^{\circ}$. The colour measurement was made by applying $0.4 \mathrm{~g}$ of juice 
or $1 \mathrm{ml}$ of juice extract in plastic white containers. CIELab parameters (CIE $1976 \mathrm{~L}^{*} \mathrm{a}^{*} \mathrm{~b}^{*}$ ) were $\mathrm{L}^{*}$ for lightness, $a^{*}$ for redness and $b^{*}$ for yellowness. The instrument was standardized with a white tile $\left(L^{*}=91.10, a^{*}=1.12\right.$ and $\left.b^{*}=1.26\right)$. Calculations of $C^{*}{ }_{a b}\left(\left(a^{* 2}+b^{* 2}\right)^{1 / 2}\right)$ for chroma and $h_{a b}$ for hue angle $\left(\arctan b^{*} / a^{*}\right)$ were made.

\subsubsection{Colour density, Polymeric colour and Percent polymeric colour}

Percent polymeric colour was determined using the method described by Giusti and Wrolstad [16]. Samples of juice extract were treated with a potassium metabisulfite solution for bleaching or with water as a control. Absorbance was read at 420, 510 and $700 \mathrm{~nm}$. Colour density (CD) was calculated using the control sample according to Equation (2), being DF the dilution factor for Equations (2) and (3).

$$
\mathrm{CD}=\left[\left(\mathrm{A}_{420}-\mathrm{A}_{700}\right)+\left(\mathrm{A}_{510}-\mathrm{A}_{700}\right)\right] \cdot \mathrm{DF}
$$

Polymeric colour (PC) was determined using the bisulfite-bleached sample according to Equation (3).

$$
P C=\left[\left(A_{420}-A_{700}\right)+\left(A_{510}-A_{700}\right)\right] \cdot D F
$$

Percent polymeric colour (\% PC) was calculated using the Equation (4).

$$
\% \mathrm{PC}=(\mathrm{PC} / \mathrm{CD}) \cdot 100
$$

\subsubsection{Kinetics model}

Monomeric anthocyanin (MAcy) degradation and the evolution of colour parameter $\mathrm{a}^{*}$ has been found to follow a first-order reaction model [19-21]:

$$
\begin{gathered}
\text { In }\left(\mathrm{C} / \mathrm{C}_{0}\right)=-\mathrm{k}_{\mathrm{MA}} \cdot \mathrm{t} \\
\text { In }\left(\mathrm{C} / \mathrm{C}_{0}\right)=-\mathrm{k}_{\mathrm{a}} \cdot \mathrm{t} \\
\mathrm{t}_{1 / 2}=-\ln 0.5 \cdot \mathrm{k}^{-1} \\
\mathrm{Q}_{10}=\left(\mathrm{k}_{2} / \mathrm{k}_{1}\right)^{10 /(\mathrm{T} 2-\mathrm{T} 1)}
\end{gathered}
$$

$\mathrm{C}_{0}$ : MAcy content and $\mathrm{a}^{*}$ colour parameter at initial time

$\mathrm{C}$ : MAcy content and $\mathrm{a}^{*}$ colour parameter after $t$ hours of heating at a given temperature.

$\mathrm{k}_{\mathrm{MA}}$ : reaction rate constant for MAcy degradation

$\mathrm{k}_{\mathrm{a}}$ : reaction rate constant for $\mathrm{a}^{*}$ degradation.

$\mathrm{t}_{1 / 2}$ : half-life time, time needed for $50 \%$ degradation of MAcy or $\mathrm{a}^{*}$ colour parameter.

$\mathrm{k}_{1}, \mathrm{k}_{2}$ : degradation rates at $\mathrm{T}_{1}$ and $\mathrm{T}_{2}$

\subsection{Data analysis}

Thermal treatment of pulps and storage of juice bottles were performed by duplicate. At selected heating and storage times samples were analysed. All the parameters studied were determined in duplicate for each juice or pulp sample, in the case of monomeric anthocyanins determination by $\mathrm{pH}$ differential method and colour measurements determinations were performed in triplicate. Average of measurements was reported. Colour parameters of elderberry extracts at initial and final time of thermal treatments were analysed by one-way analysis of variance (ANOVA) test using Infostat v.2009 (Universidad Nacional de Córdoba, Argentina). Means comparisons were carried out by Student Neuman-Keuls (SNK) test at $P<0.05$. Pearson's correlations between phenolics compounds and colour parameters were performed. 


\section{Results and discussion}

\subsection{Degradation kinetics of monomeric anthocyanins (MAcy) and a* colour parameter in elderberry pulp during heat treatment}

Elderberry pulp was characterized by an average content ( \pm standard error) of $11.8 \pm 0.1$ soluble solids $\left({ }^{\circ}\right.$ Brix) and $3.80 \pm 0.01 \mathrm{pH}$. The initial content of total phenolics in elderberry pulp was $5835 \pm 132 \mathrm{mg} / \mathrm{L}$ and this content was stable during heat treatment at all temperatures, showing retention greater than $85 \%$ for all heating temperatures.

Initial MAcy content was $1032 \pm 38 \mathrm{mg} / \mathrm{L}$. Figure 1 shows the evolution of MAcy and a* degradation following a first-order reaction model described in Equations (5) and (6). Degradation rates and half-life times ( $\left.\mathrm{t}_{1 / 2}\right)$ of monomeric anthocyanins and colour parameter $\mathrm{a}^{*}$ estimated at the different temperatures are shown in Table 1. For the colour parameter $\mathrm{a}^{*}$, the rate of degradation was about three times lower than that corresponding to the MAcy degradation at each temperature.

Q10 values obtained at $70-80^{\circ} \mathrm{C}$ were 3.27 and 3.19 for MAcy and a* colour parameter degradation; at $80-90^{\circ} \mathrm{C}$ the values were 5.02 and 4.74 for MAcy and $\mathrm{a}^{*}$, respectively. These values indicate that for a certain heat treatment time at $90^{\circ} \mathrm{C}$, an equivalent process would be obtained at $80^{\circ} \mathrm{C}$ with a process 5.02 times longer, and at $70^{\circ} \mathrm{C} 3.27$ times longer than at $80^{\circ} \mathrm{C}$. For example for MAcy degradation, a process of $1 \mathrm{~min}$ at $90^{\circ} \mathrm{C}$ is equivalent to $5.02 \mathrm{~min}$ at $80^{\circ} \mathrm{C}$ and 16.4 minutes at $70^{\circ} \mathrm{C}$.

The effect of temperature on the degradation rate constants for MAcy and a* was expressed by the linearized Arrhenius equation by plotting $\mathrm{ln} \mathrm{k}$ against $1 / \mathrm{T}$ in which the temperature dependence of $\mathrm{k}$ was quantified by the activation energy $E_{a}$ according to:

$$
\ln k=\ln A_{0}-\mathrm{E}_{\mathrm{a}} / \mathrm{RT}
$$
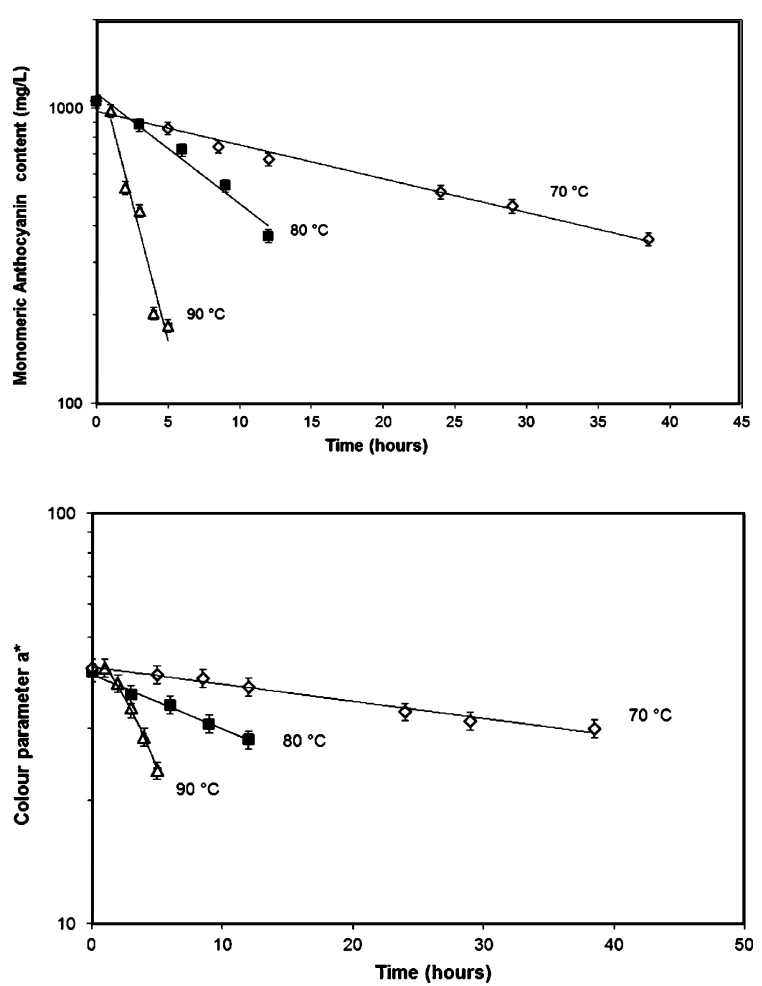

Fig. 1. Degradation of monomeric anthocyanin content and colour parameter a* in elderberry pulp during heating at 70,80 and $90^{\circ} \mathrm{C}$. Values are mean \pm standard deviations, $n=3$ for MAcy and color parameter $\mathrm{a}^{*}$. 
where $\mathrm{k}$ is the rate constant $\left(\mathrm{h}^{-1}\right), \mathrm{A}_{0}$ is the frequency factor $\left(\mathrm{h}^{-1}\right), \mathrm{E}_{\mathrm{a}}$ is the activation energy $(\mathrm{kJ} / \mathrm{mol}), \mathrm{R}$ is the universal gas constant $\left(8.314 \times 10^{-3} \mathrm{~kJ} / \mathrm{K} \mathrm{mol}\right)$ and $\mathrm{T}$ is the absolute temperature. $\mathrm{E}_{\mathrm{a}}$ value was calculated from the slope of the straight line given by Equation (8)

The calculated $E_{a}$ values were $144.6 \pm 15.2 \mathrm{~kJ} / \mathrm{mol}$ for MAcy degradation and $140.6 \pm 13.5 \mathrm{~kJ} / \mathrm{mol}$ for a* degradation, indicating that both degradation processes have the same temperature dependence.

It can be seen that although the deterioration of MAcy and $a^{*}$ have similar temperature dependence, colour degradation would occur slowly according to the values of $k$ and $t_{1 / 2}$ obtained.

Table 1 shows half-life times for MAcy $\left(\mathrm{t}_{1}\right)$ and $\mathrm{a}^{*}$ degradation $\left(\mathrm{t}_{2}\right)$, and the retention percent of $\mathrm{a}^{*}$ evaluated at $\mathrm{t}_{1}$, in relation to the initial value. The results indicate a high colour retention, showing greater retention at $90^{\circ} \mathrm{C}: 78.2$, 77.3 and $94.9 \%$ at 70,80 and $90^{\circ} \mathrm{C}$ respectively. This could be attributed to the fact that the relationship between rates of deterioration for both quality indexes, color and anthocyanins content $\left(\mathrm{k}_{\mathrm{a} *} / \mathrm{k}_{\mathrm{MAcy}}\right)$, are lower at $90^{\circ} \mathrm{C}(0.335)$ than at $80(0.354)$ or $70^{\circ} \mathrm{C}(0.364)$.

The change in percentage of polymeric colour (\% PC) during heating of elderberry pulps was also studied. In all cases an increase in \% PC at the end of heat treatment were observed, from $60 \%$ before heat treatment to $75 \%$ and $71 \%$ to $93 \%$, at $70^{\circ} \mathrm{C}, 80^{\circ} \mathrm{C}$ and $90^{\circ} \mathrm{C}$, respectively. This would indicate a greater importance of the polymeric compounds of total anthocyanins after heating.

Table 2 shows the values of colour parameters $L^{*}, a^{*}, b^{*}$ and $h_{a b}$ for extracts, at initial time and after heat treatment. As described, a decrease in colour parameter $\mathrm{a}^{*}$ (associated to red colour) was observed, an increase in the brightness $\mathrm{L}^{*}$ and in the case of heat treatments at 80 and $90^{\circ} \mathrm{C}$ an increase in $\mathrm{h}_{\mathrm{ab}}$ was observed, indicating a change of colour to more brownish tones. Fischer et al. [14] observed similar colour changes after the thermal treatment of pomegranate juice. Extracts of juice showed a decrease of $a^{*}(52 \%)$ with increase of $b^{*}(98 \%)$ and $L^{*}(4 \%)$ values, indicating a fading in colour which was ascribed to anthocyanin losses.

Table 1

Kinetic parameters $\mathrm{k}_{\text {hour }}^{-1}$ ) and $\mathrm{t}_{1 / 2}$ (hour) for thermal degradation of monomeric anthocyanins and colour parameter $\mathrm{a}^{*}$ during heating at 70 , 80 and $90^{\circ} \mathrm{C}$

\begin{tabular}{lccc}
\hline Temperature & $70^{\circ} \mathrm{C}$ & $80^{\circ} \mathrm{C}$ & $90^{\circ} \mathrm{C}$ \\
\hline $\mathrm{k}($ MAcy) & $0.0264 \pm 0.0015$ & $0.0863 \pm 0.0084$ & $0.4337 \pm 0.0286$ \\
$\mathrm{k}\left(\mathrm{a}^{*}\right)$ & $0.0096 \pm 0.0006$ & $0.0306 \pm 0.0016$ & $0.1452 \pm 0.0056$ \\
$\mathrm{t}_{1}\left(\mathrm{t}_{1 / 2}\right.$ for MAcy) & $26.25 \pm 1.49$ & $8.03 \pm 0.78$ & $1.60 \pm 0.11$ \\
$\mathrm{t}_{2}\left(\mathrm{t}_{1 / 2}\right.$ for $\left.\mathrm{a}^{*}\right)$ & $72.19 \pm 4.51$ & $22.65 \pm 1.18$ & $4.75 \pm 0.183$ \\
${ }^{1}$ Color retention $\mathrm{a}^{*}(\%)$ & $78.2 \pm 4.9$ & $77.1 \pm 4.0$ & $94.9 \pm 3.7$ \\
\hline
\end{tabular}

${ }^{1}$ Retention of colour parameter $\mathrm{a}^{*}(\%)$ related to initial value is evaluated at $\mathrm{t}_{1}$ (half-life for anthocyanin degradation). Values are mean \pm standard error.

Table 2

CIELab colour parameters of elderberry extracts at initial and final time of thermal treatment performed at constant temperature

\begin{tabular}{|c|c|c|c|c|}
\hline \multirow[t]{2}{*}{ Colour parameter } & & \multicolumn{3}{|c|}{ Temperature } \\
\hline & & $70^{\circ} \mathrm{C}$ & $80^{\circ} \mathrm{C}$ & $90^{\circ} \mathrm{C}$ \\
\hline \multirow[t]{2}{*}{$\mathrm{L}^{*}$} & Initial & $22.28 \pm 0.84^{b}$ & $22.28 \pm 0.84^{b}$ & $22.28 \pm 0.84^{\mathrm{b}}$ \\
\hline & Final & $29.81 \pm 0.82^{\mathrm{a}}$ & $29.69 \pm 1.31^{\mathrm{a}}$ & $33.62 \pm 0.09^{\mathrm{a}}$ \\
\hline \multirow[t]{2}{*}{$a^{*}$} & Initial & $41.96 \pm 0.03^{\mathrm{a}}$ & $41.96 \pm 0.03^{\mathrm{a}}$ & $41.96 \pm 0.03^{\mathrm{a}}$ \\
\hline & Final & $29.92 \pm 1.03^{b}$ & $28.12 \pm 0.58^{\mathrm{b}}$ & $23.61 \pm 0.27^{\mathrm{b}}$ \\
\hline \multirow[t]{2}{*}{$b^{*}$} & Initial & $11.78 \pm 0.73^{\mathrm{a}}$ & $11.78 \pm 0.73^{\mathrm{a}}$ & $11.78 \pm 0.73^{\mathrm{a}}$ \\
\hline & Final & $9.78 \pm 0.33^{\mathrm{a}}$ & $10.86 \pm 0.39^{\mathrm{a}}$ & $11.03 \pm 0.78^{\mathrm{a}}$ \\
\hline \multirow[t]{2}{*}{$\mathrm{h}_{\mathrm{ab}}$} & Initial & $15.66 \pm 0.91^{\mathrm{a}}$ & $15.66 \pm 0.91^{\mathrm{b}}$ & $15.66 \pm 0.91^{\mathrm{b}}$ \\
\hline & Final & $18.11 \pm 0.03^{\mathrm{a}}$ & $21.11 \pm 0.30^{\mathrm{a}}$ & $26.04 \pm 0.29^{\mathrm{a}}$ \\
\hline
\end{tabular}

Values are means $\pm \mathrm{SD}, n=3$. For each color parameter, means with different letters within the same column are significantly different $(P<0.05)$, according to SNK test. 
A good correlation was observed in the behaviour of the parameter MAcy and a* colour parameter in pulp extract during heating, showing correlation coefficients 0.86 at $70^{\circ} \mathrm{C}, 0.99$ at $80^{\circ} \mathrm{C}$ and 0.95 at $90^{\circ} \mathrm{C}$ and an overall coefficient of 0.86 .

\subsection{Elderberry juice storage}

\subsubsection{Total phenolic, monomeric anthocyanins content and antioxidant capacity}

The effect of storage on elderberry juice characteristics was evaluated at $40^{\circ} \mathrm{C}$ during 140 days in an accelerated shelf-life test. Table 3 shows the characteristics of elderberry juice at the start of storage indicating an average content of 36.8 soluble solids ( ${ }^{\circ}$ Brix) and pH 3.60. The initial content of total phenolic was $6100 \pm 305 \mathrm{mg} / \mathrm{L}$ and its concentration remained very stable during storage. At the end of storage $\left(140\right.$ days at $\left.40^{\circ} \mathrm{C}\right)$ the concentration was $70 \%$ of the initial level (Fig. 2). Monomeric anthocyanin measured by the $\mathrm{pH}$ differential method presented a low stability during storage because only approximately $10 \%$ retention $(964 \mathrm{mg} / \mathrm{L}$ to $78 \mathrm{mg} / \mathrm{L}$, initial and final concentration, respectively) was observed in the same conditions. The decrease $(\%)$ of both total phenolic and monomeric anthocyanin levels during storage are shown in Fig. 2. As can be seen, the main reduction of monomeric anthocyanin was produced during the first 30 days and then its concentration remained almost constant.

The initial antioxidant capacity was $12.2 \mathrm{mmol}$ Trolox/ $\mathrm{mL}$ and it remained stable, a small reduction (14.8\%) was observed at the end of storage. As can be seen in Fig. 2, the antioxidant capacity and total phenolic content displayed similar variations during storage with a close correlation between both measurements $(r=0.96 ; p<0.05)$. A similar outcome was observed in blueberry juice by Brownmiller et al. [22] who remarked that the antioxidant capacity values of nonclarified and clarified juices remained stable over the 6 months of storage, despite marked losses of total anthocyanins.

Table 3

Characteristics of elderberry juice at the beginning of storage

\begin{tabular}{lc}
\hline & Value \\
\hline $\mathrm{pH}$ & $3.6 \pm 0.1$ \\
Total soluble solids $\left({ }^{\circ}\right.$ Brix $)$ & $36.8 \pm 0.1$ \\
Total monomeric anthocyanins (mg/L) & $964 \pm 48$ \\
Total phenolics (mg GAE/L) & $6100 \pm 310$ \\
Total antioxidant capacity (mmol Trolox/ml) & $12.2 \pm 1.2$ \\
\hline
\end{tabular}

Values are means \pm standard error.

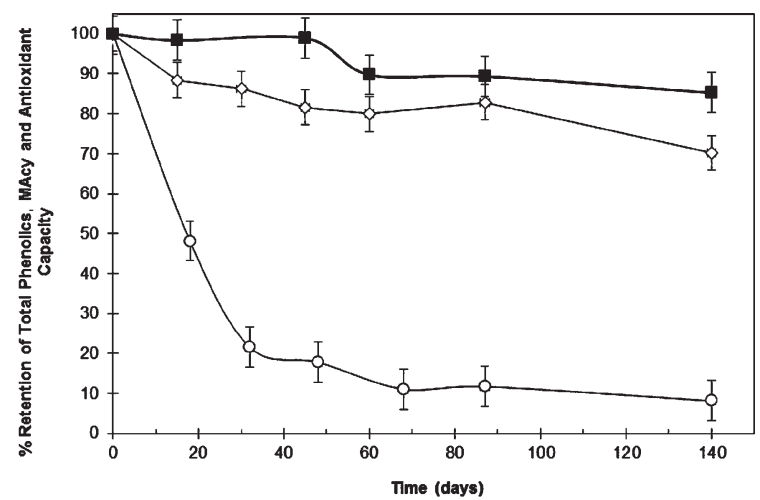

Fig. 2. Changes in the Retention $(\%)$ of Total phenolics $(\diamond)$, Monomeric anthocyanins (०) and Antioxidant Capacity during storage period (140 days) at $40^{\circ} \mathrm{C}$, considering the initial values as $100 \%$ retention. Values represent mean \pm standard deviations (duplicates). 

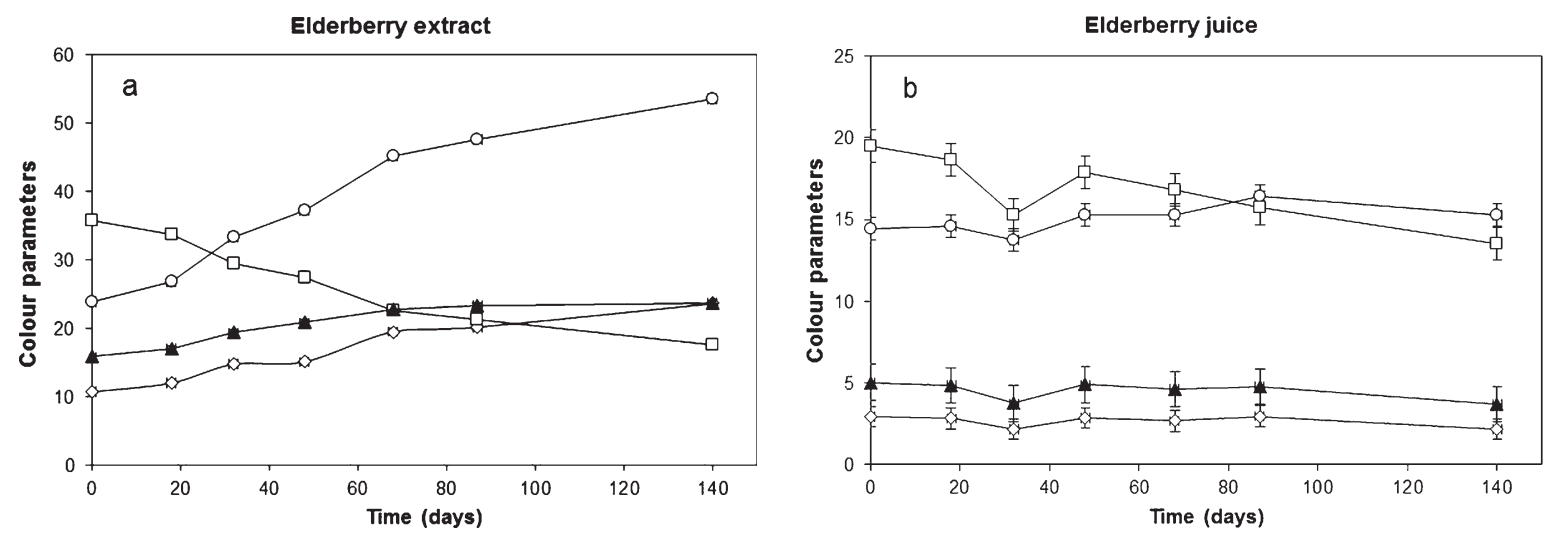

Fig. 3. CIELab colour space values. Changes in the colour parameters $L^{*}$ (lightness, $\diamond$ ), a* (redness, $\square$ ), b*(yellowness, $\Delta$ ), $h_{a b}($ hue angle, $\circ$ ) during storage ( 140 days) at $40^{\circ} \mathrm{C}$ for elderberry juice (a) and elderberry alcoholic extract (b). Values are mean \pm standard deviations, $n=3$.

Total anthocyanins and cyanidin-3-glucoside content were determined by HPLC during the storage period at $40^{\circ} \mathrm{C}$. The initial total anthocyanins content determined by HPLC was $759.1 \mathrm{mg} / \mathrm{L}$ and its concentration decreased very quickly during the first 15 days, with a reduction of $38 \%$ in this period. Afterward, the content level remained almost constant, shown by the end of storage the concentration was $314.1 \mathrm{mg} / \mathrm{L}$ which represented $41 \%$ of initial concentration. The results showed that cyanidin 3-glucoside was the main compound, obtaninig an initial value of $311 \mathrm{mg} / \mathrm{L}$, that represents $41.7 \%$ of total anthocyanins. Cy3glc decreased by approximately $70 \%$ during the first 15 days and was not detected at 60 days.

\subsubsection{Colour evaluation}

The evolution of elderberry juice colour during storage is shown in Fig. 3. As can be seen only a small reduction (31\%) of a* parameter (red tone marker) was observed at the end of storage. Samples at initial time showed an intense red tone $\left(a^{*}=19.5 ; h^{\circ}=14.3\right)$ with low purity $\left(C^{*}=20.2\right)$ and lightness $\left(L^{*}=2.9\right)$, and changes in the parameters were not visible. It is to be noted that colour changes were more evident in the juice extract as is shown in Fig. 3, in the same manner as that observed in pulps. The decrease of $\mathrm{a}^{*}$ was fastest during the first 60 days of storage, $\Delta \mathrm{a}^{*}=-13.2$ (37\% reduction), the diminution slowed over the final 80 days, eventually, losing $51 \%$ of the initial value (140 days). The increase in $b^{*}$ was about $43 \%\left(\Delta b^{*}=7\right)$ and $L^{*}$ doubled in value in 60 days $\left(\Delta \mathrm{L}^{*}=9\right)$. $h^{\circ}$ was the parameter which most increased during the total time of storage $\left(\Delta \mathrm{h}^{\circ}=30\right)$, demonstrating a change to brownish tones, similarly that observed during heating.

Colour density (CD) decreased from 60 to 40, and \% PC increased from 43\% to $87 \%$ at the end of storage, relating to polymeric compound formation. These changes were higher during the first 30 days of storage.

\subsubsection{Correlations between phenolic compounds and colour parameters}

Pearson correlation coefficients $(p<0.01)$ among colour parameters and total phenolics $(\mathrm{TP})$, monomeric anthocyanins (MAcy) and percent polymeric color (PC \%) in juice extracts during storage at $40^{\circ} \mathrm{C}$ showed that:

Phenolic and anthocyanin content are positively correlated with a* and negatively with $b^{*}, L^{*}$ and $h_{a b}$; percent polymeric colour is correlated negatively with $\mathrm{a}^{*}$ and $\mathrm{C}^{*}$, and positively with $\mathrm{b}^{*}, \mathrm{~L}^{*}$ and $h_{a b}$.

$\%$ PC evolution was inversely correlated with TP and MAcy with $\mathrm{R}=-0.99$ and $-0.94(p<0.05)$, respectively. High correlations were also observed between antioxidant capacity and colour parameters: $h_{a b}$ and $\mathrm{C}^{*}(-0.99$ and $0.99, p<0.01)$. Thus, during storage juice colour changed from intense red to yellow-brownish red associated with the decay of phenolics and anthocyanins and the increment of polymeric forms. Based on these results, the colour parameters would be good estimators of the evolution of total phenolics, anthocyanins and polymeric forms during storage. 


\subsubsection{Degradation kinetics of monomeric anthocyanins (MAcy) and a* colour parameter in elderberry juice during storage}

Degradation rates of monomeric anthocyanins and colour parameter a* at $40^{\circ} \mathrm{C}$ were calculated using first-order kinetics (Equations 4 and 5). The degradation rate values (k) obtained were $0.025 \mathrm{~d}^{-1}$ for MAcy and $0.0064 \mathrm{~d}^{-1}$ for colour parameter $\mathrm{a}^{*}$. Similar to what was observed during heating, colour degradation rate was considerably lower than anthocyanin reduction. Half - life values were 27.7 days for MAcy and 108 days for a* degradation. Considering a $\mathrm{Q}_{10}$ value of 2.5 between $25-40^{\circ} \mathrm{C}$ from bibliographical sources (11, 12 - Kirca et al., 2006; 2007) a $50 \%$ of reduction would be observed at 120 days for MAcy and at 432 days for colour parameter $\mathrm{a}^{*}$ at $25^{\circ} \mathrm{C}$. However, a high retention of polyphenols and antioxidant capacity would be observed at the end of storage.

\subsection{Discussion}

The present results show that the anthocyanin content significantly decreased both during heating and storage. However, total phenolic content are more stable, showing high retention values at the end of heating and storage. Stability of the antioxidant capacity was also observed during storage. This result agreed to Fischer et al. (14), who found that the total phenolic content was not markedly lowered upon heating pomegranate juices despite a significant decrease in anthocyanin content during heat treatment between 60 and $90^{\circ} \mathrm{C}$.

The changes in colour during heating and storage time were less than anthocyanin degradation. Colour stabilization phenomena may be produced by different reactions such as co-pigmentation of anthocyanins with other compounds (co-pigments), considered one of the main mechanisms of stabilization of colour in plants [23-26]. In this phenomenon, the pigments and other colourless organic compounds or metallic ions form molecular or complex associations, generating a change in colour intensity. In the case of intramolecular copigmentation, the covalent acylation of the anthocyanin molecule stabilizes the pigment, probably because the reactivity of the carbon C- 2 and C-4 with nucleophilic reactants, e.g. water molecules, is hindered [27].

The increase in observation of the percentage of polymeric colour may indicate the formation of condensation reactions between anthocyanins and other polymeric compounds such as procyanidins, resulting in the formation of polymerized phenolic compounds that can be detected by the Folin method [10]. This phenomenon may explain the stability observed in the phenolic content.

These observations would be consistent with the increase in the colour parameter $h_{a b}$ and visual observations that indicate the more brownish colour of the samples. Chaovanalikit and Wrolstad [28] reported that total anthocyanins in canned bing cherries decreased by $40 \%$ after 5 months storage at $22^{\circ} \mathrm{C}$, although there was not a significant reduction in total phenolics. They also observed an increase in percent polymeric colour with canning from $13 \%$ to $40 \%$. Similarly total anthocyanins in canned strawberries declined $69 \%$ and percent polymeric colour increased from $7 \%$ to $33 \%$ after 60 days of storage at room temperature [29].

The activation energies $\left(\mathrm{E}_{\mathrm{a}}\right)$ values obtained for the thermal degradation of anthocyanins and colour $(144.6 \pm 15.2$ and $140.5 \pm 13.5 \mathrm{~kJ} / \mathrm{mol}$ ) indicate significant temperature dependence for these degradation processes. Other authors have reported $E_{a}$ values in the same order for anthocyanin degradation in several fruit and vegetables: $71.9 \mathrm{~kJ} / \mathrm{mol}$ for grapefruit [11], $74.8 \mathrm{~kJ} / \mathrm{mol}$ for acerola pulp [30], $58.95 \mathrm{~kJ} / \mathrm{mol}$ for blackberry juice [31], $80.4 \mathrm{~kJ} / \mathrm{mol}$ for blueberry [32] and $94.4 \mathrm{~kJ} / \mathrm{mol}$ for strawberry pure [33]. $\mathrm{Q}_{10}$ values have also been reported in the same range of temperatures, although slightly lower than those obtained in the present work: 2.3 between $70-80^{\circ} \mathrm{C}$ [11], 2.95 between $60-70^{\circ} \mathrm{C}$ [32].

These values indicate that the selection of temperature and time have a significant effect on the final characteristics of the thermally treated product. Enzyme inactivation is one of the objectives of applying a heat treatment in such products based on fruits. The processes of enzyme inactivation such as polyphenol oxidase (PPO) or peroxidase (PDO) have much higher temperature dependence with values of $E_{a}$ between 214-295 kJ/mol [34-36]. This would indicate a greater suitability of applying a heat treatment at higher temperatures for short periods (e.g. $\left.90^{\circ} \mathrm{C}\right)$.

\section{Conclusions}

The kinetic parameters calculated for elderberry juice can be used to design a thermal treatment to obtain a high retention of attractive colour and bioactive compounds. While a significant dependence on temperature $\left(\mathrm{E}_{\mathrm{a}}\right)$ was 
observed, it is less than other factors such as enzyme inactivation which is necessary to apply in fruit products. This implies that an increase in heat treatment temperature has a greater effect on the enzymes inactivation than in quality parameters or bioactive compounds concentration. The antioxidant capacity and a high percentage of colour are retained during the long storage time (15 months).

\section{Acknowledgments}

The authors would like to thank Frutas del Sur Andino S.A. (Río Negro, Argentina) for donating the commercial juices used in this study that was funded by CONICET (Project PIP -CONICET N 052 ).

\section{References}

[1] Vulić JJ, Vračar LO, Šumić ZM. Chemical characteristics of cultivated elderberry fruit. Acta Periodica Technologica. 2008;39:85-90.

[2] Pérez-Jiménez J, Neveu V, Vos F, Scalbert A. Identification of the 100 richest dietary sources of polyphenols: An application of the Phenol-Explorer database. European Journal of Clinical Nutrition. 2010;64:S112-20.

[3] Granato D, Karnopp AR, van Ruth SM. Characterization and comparison of phenolic composition, antioxidant capacity and instrumental taste profile of juices from different botanical origins. Journal of the science of food and agriculture. 2014. In press. DOI: 10.1002/jsfa.6910.

[4] Thorne Research. Sambucus nigra (Elderberry). Alternative Medicine Review. 2005;10:51-55.

[5] Veberic R, Jakopic J, Stampar F, Schmitzer V. European elderberry (Sambucus nigra L.) rich in sugars, organic acids, anthocyanins and selected polyphenols. Food Chemistry. 2009;114:511-5.

[6] Netzel M, Stintzing FC, Quaas D, Strass G, Carle R, Bitsch R, Bitsch I, Frank T. Renal excretion of antioxidative constituents from red beet in humans. Food Research International. 2005;38:1051-58.

[7] Wrolstad, RE, Durst RW, Lee J. Tracking color and pigment changes in anthocyanin products. Trends in Food Science \& Technology. 2005; $16: 423-28$

[8] Busso Casati C, Sénchez V, Baeza R, Magnani N, Evelson P, Zamora MC. Relationships between colour parameters, phenolic content and sensory changes of processed blueberry, elderberry and blackcurrant commercial juices. International Journal of Food Science and Technology. 2012;47:1728-36.

[9] Boranbayeva T, Karadeniz F, Yilmaz E. Effect of storage on anthocyanin degradation in black mulberry juice and concentrates. Food and Bioprocess Technology. 2014;7:1894-1902.

[10] Patras A, Brunton NP, O’Donnell C, Tiwari BK. Effect of thermal processing on anthocyanin stability in foods; mechanisms and kinetics of degradation. Review. Trends in Food Science \& Technology. 2010;21:3-11.

[11] Kirca A, Özkan M, Cemeroğlu B. Stability of black carrot anthocyanins in various fruit juices and nectars. Food Chemistry. 2006;97:598-605.

[12] Kirca A, Őzkan M, Cemeroğlu B. Effects of temperature solid content and pH on stability of black carrot anthocyanins. Food Chemistry. 2007;101:212-18.

[13] Kara Ş, Erçelebi EA. Thermal degradation kinetics of anthocyanins and visual color of Urmu mulberry (Morus nigra L.). Journal of food Engineering. 2013;116:541-47.

[14] Fischer UA, Carle R, Kammerer DR. Thermal stability of anthocyanins and colourless phenolics in pomegranate (Punica granatum L.) juices and model solutions. Food Chemistry. 2013;138:1800-09.

[15] Waterhouse AL. Determination of total phenolics. In R. E. Wrolstad editor. Current Protocols in Food Analytical Chemistry. New York: Wiley \& Sons; 2001. pp. I1.1.1-I1.1.8

[16] Giusti MM, Wrolstad RE. Characterization and measurement of anthocyanins by UV-visible spectroscopy. In: R. Wrolstad, T. Acree, H. An, E. Decker, M. Penner, D. Reis, S. Schawrtz, C. Shoemaker \& P. Spoms, editors. Current Protocols in Food Analytical Chemistry (1st edn). New York: John Wiley and Sons, Inc; 2001. p F1.2.1-F1.2.13.

[17] Hager TJ, Howard LR, Liyanage R, Lay JO, Prior RL. Ellagitannin composition of blackberry as determined by HPLC-ESI-MS and MALDI-TOF-MS. Journal of Agricultural and Food Chemistry. 2008;56:661-69.

[18] Sánchez-Moreno C, Larrauri J, Saura-Calixto F. A procedure to measure the antiradical efficiency of polyphenols. Journal of the Science of Food Agriculture. 1998;76:270-76.

[19] Maskan M. Production of pomegranate (Punica granatum L.) juice concentrate by various heating methods: Colour degradation and kinetics. Journal of Food Engineering. 2006;72:218-24.

[20] Yang Z, Han Y, Gu Z, Fan GZ. Thermal degradation kinetics of aqueous anthocyanins and visual color of purple corn (Zea mays L.) cob. Innovative Food Science \& Emerging Technologies. 2008;9:341-47.

[21] Özşen D, Erge HS. Degradation kinetics of bioactive compounds and change in the antioxidant activity of wild strawberry (Fragaria vesca) pulp during heating. Food and Bioprocess Technology. 2013;9:2261-67.

[22] Brownmiller C, Howard LR, Prior RL. Processing and storage effects on monomeric anthocyanins, percent polymeric color and antioxidant capacity of processed blueberry products. Journal of Food Science. 2008;73:H72-79. 
[23] Davies AJ, Mazza G. Copigmentation of simple and acylated anthocyanins with colorless phenolic compounds. Journal of Agricultural and Food Chemistry. 1993;41:716-20.

[24] Mazza G, Brouillard R. Recent developments in the stabilization of anthocyanins in food products. Food Chemistry. 1987;25:207-25.

[25] Mazza G, Brouillard R. The mechanism of copigmentation of anthocyanins in aqueous solutions. Phytochemistry. 1990;29:1097-102.

[26] Bakowska A, Kucharska AZ, Oszmianski J. The effects of heating, UV irradiation, and storage on stability of the anthocyanin-polyphenol copigment complex. Food Chemistry. 2003;81:349-55.

[27] Rein MJ. Copigmentation reactions and color stability of berry anthocyanins (dissertation). EKT series 1331. University of Helsinki, Department of Applied Chemistry and Microbiology. 2005. 88+34 pp.

[28] Chaovanalikit A, Wrolstad RE. Total anthocyanins and total phenolics of fresh and processed cherries and their antioxidant properties. Journal of Food Science. 2004;69:67-72.

[29] Ngo T, Wrolstad RE, Zhao Y. Color quality of Oregon strawberries-Impact of genotype, composition, and processing. Journal of Food Science. 2007;72:25-32.

[30] Mercali GD, Pez Jaeschke D, Tessaro IC. Degradation kinetics of anthocyanins in acerola pulp: Comparison between ohmic and conventional heat treatment. Food Chemistry. 2013;136:853-7.

[31] Wang WD, \& Xu SY. Degradation kinetics of anthocyanins in blackberry juice and concentrate. Journal of Food Engineering. 2007;82:271-5.

[32] Pereira Kechinski C, Ramos Guimaraes V, Zapata Noreña C, Tessaro I, Ferreira Marczak L. Degradation kinetics of anthocyanin in blueberry juice during thermal treatment. Journal of Food Science. 2010;75(2):173-6.

[33] Verbeyst L, Oey I, van der Plancken I, Hendrickx M, van Loey A. Kinetic study on the thermal and pressure degradation of anthocyanins. Food Chemistry. 2010;123:269-74.

[34] Fortea MI, Lopez-Miranda S, Serrano-Martinez A, Carreño J, Núñez-Delicado, E. Kinetic characterization and thermal inactivation study of polyphenol oxidase from table grape (Crimson seedless). Food Chemistry. 2009;113:1008-14.

[35] Terefe N, Yang YH, Knoerzer K, Buckow R, Versteeg C. High pressure and thermal inactivation kinetics of polyphenol oxidase and peroxidase in strawberry puree. Innovative Food Science and Emerging Technologies. 2010;11:52-60.

[36] Cheng XF, Zhang M, Adhikari B. The inactivation kinetics of polyphenol oxidase in mushroom (Agaricus bisporus) during thermal and thermosonic treatments. Ultrasonics sonochemistry. 2013;20:674-79. 